\title{
Uma Nova Reflexão Sobre A Atribuição De Poderes Investigatórios Do Ministério Público $^{1}$
}

Guilherme Zuanazzi

Graduado em Direito pela Unesp, Mestrando em Direito pela Unesp e bolsista CAPES

guizuanazzi@yahoo.com.br

\section{RESUMO}

O presente artigo pretende abordar a questão da admissibilidade de atribuição investigatória do Ministério Público no processo penal brasileiro, muito além das características institucionais, ressaltando a importância da análise do sistema processual penal vigente para a compreensão das dimensões de uma inserção desta atribuição no modelo processual adotado pelo Código de Processo Penal de 1941, exclusivamente por exigências de efetividade, e suas respectivas conseqüências perante a conformação constitucional de um devido processo criminal.

Palavras-Chave: Modelo processual penal; Investigação criminal; Ministério Público; Devido processo legal.

\section{ABSTRACT}

Title: A new reflection upon the attribution of Investigative Powers to the Attorney General's

Office.

The present paper intends to raise the question of the admissibility of the Attorney General's Office investigative attribution to the Brazilian penal law practice, which goes far beyond the institutional characteristics and highlights the importance of the current system practice for the understanding of the dimensions of this insertion on the practice model adopted by the 1941 Penal Code Practice. That happened exclusively because of the demand for effectiveness and its respective consequences concerning the constitutional conformity to a certain criminal suit.

Key-words: Penal Practice Model, Criminal Investigation, Attorney General's Office, Certain Criminal Suit.

\footnotetext{
${ }^{1} \mathrm{O}$ presente artigo é fruto de monografia apresentada como requisito para conferência de grau de bacharel, sob orientação do Prof. ${ }^{\circ}$ Dr. ${ }^{\circ}$ Fernando Andrade Fernandes, na Faculdade de Direito, História e Serviço Social, da Universidade Estadual Paulista "Júlio de Mesquita Filho", e desenvolvida com o fomento da Fundação de Amparo à Pesquisa do Estado de São Paulo - FAPESP.
} 
A questão da admissibilidade da atribuição dos poderes investigatórios do Ministério Público, no âmbito criminal, encontrou-se na ceara do Supremo Tribunal Federal, onde, apesar de algumas decisões de suas egrégias turmas, em ambos os sentidos ${ }^{2}$, aguardava decisão definitiva da Suprema Corte.

O julgamento versava a respeito do recebimento de denúncia contra o Deputado

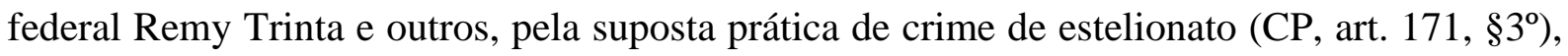
considerando que os fatos foram apurados por meio de investigações efetivadas no âmbito do Ministério Público Federal, consubstanciadas no Inquérito n. 1968.

O processo teve início, em 15 de outubro de 2003, com a rejeição da denúncia pelo Relator Ministro Marco Aurélio por entender que: "o órgão ministerial não possui competência para realizar diretamente investigações na esfera criminal, mas apenas de requisitá-las à autoridade policial competente.”3

O Sr. ${ }^{\circ}$ Ministro Nelson Jobim manifestou-se da mesma forma.

Em contraposição, o Min. Joaquim Barbosa, em voto-vista, recebeu a denúncia entendendo que o Parquet, por força do que dispõe o inciso III, do art. 129 da CF, tem competência para instaurar procedimento investigativo sobre questão que envolva interesses difusos e coletivos, salientando que:

[...] essa atribuição decorre não da natureza do ato punitivo que resulta da investigação, mas do fato a ser investigado sobre bens jurídicos cuja proteção a CF lhe conferiu. Esclareceu que a outorga constitucional, ao parquet, da titularidade da ação penal implicaria a dos meios necessários ao alcance do seu múnus, estando esses meios previstos constitucionalmente (CF, art. 129, IX) e legalmente (LC 75/93, art. 8º V; Lei 8.625/93, art. 26). Asseverou que, apesar do Ministério Público não ter competência para presidir o inquérito policial, de monopólio da polícia, a elucidação dos crimes não se esgotaria nesse âmbito, podendo ser efetivada por vários órgãos administrativos, tendo em conta o disposto no parágrafo único do art. $4^{\circ}$ do CPP. Ressaltou que a premissa de que o art. $144, \S 1^{\circ}$, IV, da CF teria estabelecido monopólio investigativo em prol da polícia federal, poria em cheque várias estruturas administrativas e investigativas realizadas por diversos órgãos no sentido de combater uma série de condutas criminosas. ${ }^{4}$

Os Ministros Eros Grau e Carlos Britto acompanharam a divergência.

No mesmo sentido das jurisprudências “menores”, o Supremo procura legitimar a atividade investigatória do Ministério Público partindo da análise das atribuições do Parquet, decorrentes do seu novo perfil institucional - dado pela Constituição de 1988-, no sentido de estender-lhe poderes relacionados à persecução criminal, reforçando este argumento com a refutação do mito da exclusividade investigatória da autoridade policial, sem antes, verificar

\footnotetext{
${ }^{2}$ MS 21729/DF, Relator Ministro Marco Aurélio de Mello, $1^{\text {a }}$ Turma; RECR 205473/AL, Relator Ministro Carlos Velloso, $2^{\text {a }}$ Turma; RE 233072/RJ, Relator Ministro Néri da Silveira, $2^{\text {a }}$ Turma.

${ }^{3}$ Informativo n. 325 do STF. www.stf.com.br.

${ }^{4}$ Informativo n. 325 do STF. www.stf.com.br.
} 
as implicações desta inserção num campo tão problemático e ambíguo quanto se revela o sistema processual penal brasileiro.

Tal pleito - pela evidente atribuição da investigação do Ministério Público - busca esteio na recepção processual do preceito constitucional, inscrito no art. 129, inc. I, que permitiu ao Ministério Público aproximar-se das investigações preparatórias, conforme atesta Fauzi Hassan Choukr ${ }^{5}$ “[...] esta nova visão acusatória enaltece a participação do Ministério Público na fase preparatória, na medida em que o coloca como destinatário das investigações e controla externamente a atividade policial [...]”.

Este pensamento conduz, partindo de um raciocínio pouco cauteloso, à conclusão de que, mais do que uma acentuação sistemático-acusatória, a titularidade exclusiva da ação penal pública do $\mathrm{MP}^{6}$ veio trazer um prestígio institucional, elevando o órgão à condição de plenos poderes. No entanto, não se deve esquecer que a acusatoriedade proposta pela Constituição ao modelo processual penal, no que tange sua diretriz democrática, mas do que atribuir a acusação a órgão diverso da jurisdição, veio para efetivar as garantias processuais do acusado, colocando-o como partícipe atuante em todo o processo, desde o momento em que haja alguma periclitação de restrição ao seu direito de liberdade. ${ }^{7}$

No que tange, ainda, a esta conformação político-criminal, diga-se incompleta, do processo penal ao liame constitucional, existem diversos exemplos no Código Processual Penal vigente em que é dada força maior às atribuições e iniciativas do órgão acusador, e não ao acusado da mesma forma. ${ }^{8}$

Talvez esta adequação incompleta, que surge no momento da construção de categorias processuais penais, se dê muito em razão de um anseio precipitado de sanar os déficits de eficiência da atividade persecutória, perante os novos aspectos da chamada "delinqüência da

\footnotetext{
${ }^{5}$ CHOUKR, Fauzi Hassan. As garantias constitucionais na investigação criminal. 425 f. Dissertação (Mestrado em Processo Penal) - Faculdade de Direito, Universidade de São Paulo, São Paulo, 1993, p.95.

${ }^{6}$ Leia-se Ministério Público.

${ }^{7}$ Das observações acima, quer-se, em verdade, aclarar o entendimento das razões que motivam o legislador constituinte atribuir, privativamente, a ação penal ao órgão do MP e que dirá, atribuir-lhe um pretenso poder investigatório. Razões estas, que se orientam muito além de um merecimento institucional que considere as capacidades e recursos estruturais. Mas sim, com vistas ao aperfeiçoamento sistemático de toda a estrutura processual penal, o que se percebe como sendo o alinhamento dos sistemas processuais de matriz francesa (mistos) a modelos de predominância acusatória, cujo movimento evolutivo é constatado pelas diversas reformas processuais no final da década de oitenta e noventa, de que são exemplos os ordenamentos italiano e português. Quer-se, portanto, de posse deste entendimento, ressaltar a importância da análise da questão em apresso na perspectiva do modelo processual adotado.

${ }^{8}$ Exemplo ainda na fase preliminar, está no art. 13, inc. II e art. 14, conjuntamente, cujos preceitos vinculam a autoridade policial ao cumprimento compulsório de diligências requisitadas pelo Ministério Público, no caso, e, em contrapartida, condicionam a realização das mesmas diligências - requeridas pelo indiciado -, ao juízo de admissibilidade desta autoridade, respectivamente.
} 
globalização”" , especialmente o que diga respeito ao crime dito organizado e de corrupção administrativa.

O efeito deste desequilíbrio na relação dos interesses persecutórios com o direito de liberdade do imputado projeta-se, no âmbito da posição jurídica dos sujeitos processuais, na forma do implemento de um órgão acusador forte e independente das “amarras processuais”, sem maiores atenções ao restante da implementação constitucional, que diz respeito à proteção do acusado.

Em suma, consubstancia-se o pensamento coorporativo de que é mais importante um MP forte e desigual, porque capaz, do que o imputado com suas garantias processuais efetivamente asseguradas. ${ }^{10}$

O resultado deste imbróglio revela-se num processo escatológico: “predominantemente acusatório, mas não de todo pouco inquisitório, onde muitas vezes uma atribuição tipicamente acusatória acaba por reforçar toda uma forma inquisitiva”, em que o maior prejuízo recai sobre a parte mais frágil e em condições reais de ação menos favoráveis, o acusado "em geral”.

Portanto, nesta linha, corre-se o risco de, na ânsia por eficiência e excessiva confiança na tão promissora instituição do MP, transformar o órgão garantidor da ordem pública e do regime democrático em um ditador dos interesses do povo, já que são estas as implicações advindas da inserção de um órgão que dispõe livremente dos meios de prova, num momento processual lato senso, de clara restrição à participação da parte contrária.

Certamente, “o tiro sairia pela culatra” e atingiria a higidez de um devido processo legal e seu fim direto (a manutenção das garantias processuais do indivíduo sujeito às investigações).

Em socorro a esta grave conseqüência, vem a proposta do presente artigo de ressaltar a relevância do modelo processual penal adotado para o encaminhamento da questão.

\footnotetext{
${ }^{9}$ Sobre a configuração deste incremento da criminalidade, ver em SILVA SÁNCHEZ, Jesus-María. A expansão do direito penal: aspectos da política criminal nas sociedades pós-industriais. (Trad. Luiz Otávio de Oliveira Rocha) São Paulo: RT, 2002, p.76-80.

${ }^{10}$ Ponderando a respeito da eterna antinomia entre os vetores de eficiência e garantia, Fernando A. Fernandes, enxerga o cerne desta “oscilação” de preocupações político-criminais na própria organização política estrutural, na qual estão conjugados princípios de um Estado de Direito (vetor garantia) e exigências de um Estado Social (vetor eficiência), e com base na experiência portuguesa, propõe "uma adequada composição entre os interesses da sociedade representados pelo poder democrático do Estado, a partir do limite intransponível da proteção da dignidade humana. Ou seja, o interesse no eficaz funcionamento do sistema da justiça penal deve ir até o limite em que seja intocada a dignidade humana." Devendo ser estendida tal premissa a "todas as questões estruturais do processo penal”. FERNANDES, Fernando A. Premissa fundamental para uma reforma global do processo penal. Boletim Ibccrim. ano 9, n. 102, maio. São Paulo, 2001, p.14.
} 
Neste sentido, a partir do estudo do direito comparado ${ }^{11}$, é possível verificar ser 0 órgão acusador investigante intrínseco ao modelo predominantemente acusatório, além de ser necessário o implemento de mecanismos paralelos à atuação investigativa do promotor público que compensem a ausência de participação da parte defensora na fase prévia ${ }^{12}$, sendo esta a forma adequada de efetivar uma situação de equilíbrio final entre as partes.

Tais mecanismos consubstanciam-se, notadamente, no âmbito da produção e valoração dos elementos de informação produzidos pelo promotor investigador, cuja máxima condiciona a admissão de valor probatório aos elementos produzidos sob o crivo do contraditório prévio. $^{13}$

\footnotetext{
${ }^{11}$ Especificamente dos modelos processuais penais norte-americano e italiano. Para a análise mais detalhada de cada um dos modelos: DELMAS-MARTY, Mireille (org.) Processos Penais da Europa. (trad. Fauzi Hassan Choukr) Rio de Janeiro: Lumen Juris, 2005; FRIEDMAN, Lawrence M. Introducción al derecho norteamericano. Trad. Joan Vergé i Grau. Universidad de Stanford. Espanha : Librería Bosh; RODRIGUEZ GARCIA, Nicolás. A justiça penal e as formas de transação no direito norte-americano: repercussões. Revista Brasileira de Ciências Criminais. n.13, jan-mar., São Paulo: RT 1996; CASSEL, Douglass. El sistema processal penal de los Estados Unidos de America. Criminalia. Ano LXIX, n.2, may-ago. México: Porrúa, 2003; BASILICO, Ricardo, El procedimento penal en los Estados Unidas. Revista de Ciencias Penales. v.5, [s.i.]: Mario A. Viera, 2000; CONSO, Giovanni (org.) Commow law e processo penale. n.28, Milano: Giuffrè, 1974; AMODIO, Ennio; BASSIOUNI, M. Cherif. (org.) Il processo penale negli stati uniti d'america. Milano: Giuffrè, 1988; AMODIO, Ennio. O modelo acusatório no novo código de processo penal italiano. Revista de Processo. ano.15, n.59, jul-set. São Paulo: RT, 1990; UBERTIS, Giulio. Sul progetto preliminare del codice di procedura penale. Rivista Italiana di Diritto e Procedura Penale. Milano: Giuffrè, 1988; FERNANDES, Fernando A. O processo penal como instrumento de política criminal. Coimbra: Almedina, 2001; LOZZI, Gilberto. Profili funzionali e aspetti struturali delle 'indagini preliminari. Rivista Italiana di Diritto e Procedura Penale. v.XXXIII. Milano: Giuffrè, 1990; ZAGREBELSKY, Vladimiro. Modello accusatorio e deontologia dei comportamenti processuali nella prospettiva comparatistica. Rivista Italiana di Diritto e Procedura Penale. Milano: Giuffrè, 1993; COLOMBO, Gherardo. L'acquisizione degli elementi di prova nelle indagini preliminari. Rivista Italiana de Diritto e Procedura Penale. anno XXXV, Milano: Giuffrè, 1992.

${ }_{12}$ Dentre os mecanismos mencionados, o discovery compreende a determinação para o promotor investigador informar o órgão de defesa da existência de qualquer elemento que indique possível absolvição do acusado, como forma de compensar os necessários momentos de restrição da participação da defesa na respectiva fase, conjuntamente, atribui-se ao acusado o privilege against self-incrimination, conhecido como um instituto de autopreservação, que o exonera do fornecimento de material ou declaração que lhe seja desfavorável, também no mesmo sentido compensatório. MOREIRA, José Carlos Barbosa. O processo penal norte-americano e sua influência. Revista Brasileira de Direito Comparado do Instituito de Direito Comparado Luso-Brasileiro. n.19, Rio de Janeiro: Dinigraf, 2001, p.234.

${ }^{13}$ Ademais, no que se refere especificamente à atribuição de valor probatório aos elementos de informação produzidos na fase investigatória prévia, como disposição dogmática hábil na manutenção da paridade de armas entre as partes por todo o processo penal, realiza-se, ao final desta fase, uma audiência preliminar presidida por juiz próprio, a fim de verificar a legalidade da aquisição dos elementos produzidos pelo órgão ministerial, momento em que devem ser suprimidas as provas obtidas de maneira ilegal, e submeter a contraditório os demais. BASILICO, Ricardo. op. cit., p.82. No que tange ainda, aos regramentos para a concessão de valor probatório aos elementos de informação produzidos na fase preliminar, é imprescindível a participação da defesa na elaboração de elementos que tenham como objeto provas irrepetíveis.

No modelo processual penal italiano, a situação acima, consubstancia-se na figura do incidente probatório, como única forma de produção de elementos de informação com valor probatório, ainda na fase preliminar. Especificamente sobre este instituto: CORRÊA, Cristiane da Rocha. O princípio do contraditório e as provas irrepetíveis no inquérito policial. Revista Brasileira de Ciências Criminais. n.60, ano.14, mai-jun. São Paulo: RT, 2006; LOZZI, Gilberto. op. cit.
} 
Os modelos norte-americano e italiano admitem a atribuição investigativa ao órgão acusador, primando sempre, pela isonomia entre as partes e, conseqüentemente, pela forma mais próxima à imparcialidade do magistrado ${ }^{14}$.

De posse desta constatação, quanto à experiência estrangeira e a partir da definição do modelo processual penal vigente, bem como pelo contraponto com o modelo constitucional adotado, estaremos habilitados para analisar a possibilidade de atribuir ao Ministério Público a investigação criminal.

Quanto ao modelo processual adotado, o inquérito policial - elaborado a partir de uma codificação de orientação repressora e autoritária ${ }^{15}$-, fadou-se como um procedimento cuja essência (administrativo, sigiloso e inquisitivo) não admite qualquer nível de implemento contraditório, sob pena de frustrar seu objetivo principal em esclarecer o fato e a autoria do possível delito. Tem-se, então, um procedimento marcado pelo tratamento desigual entre seus componentes $^{16}$.

Tal quadro dogmático vem justificado pelo esclarecimento de Geraldo Prado ${ }^{17}$, segundo o qual: “o Processo Penal Brasileiro ainda está ligado à idéia de que a jurisdição penal está inserida no programa de segurança pública do Estado e não dirigida à defesa das garantias processuais”.

Assim, é possível identificar, especificamente na fase do inquérito policial brasileiro, o evidente predomínio do vetor eficiência em detrimento da função de garantia do processo penal.

No entanto, com o advento da Constituição de 1988, alterou-se a orientação do processo penal, no sentido de também buscar a efetivação da tutela às liberdades do réu. ${ }^{18}$

\footnotetext{
${ }^{14}$ Especificamente no modelo italiano, dois expedientes contribuem diretamente para a manutenção do mínimo de imparcialidade objetiva do magistrado, em primeiro lugar, a criação do giudizio di indagini preliminar (GIP), juiz atuante na fase preliminar, distinto da figura do magistrado da causa, responsável pelo controle jurisdicional da atuação do promotor investigante; num segundo momento, cuida-se para que haja a divisão fascicular dos autos, na qual os elementos produzidos na fase preliminar são separados da peça informativa da qual o magistrado, que presidirá a instrução criminal e julgar a causa, tomará contato.

${ }^{15}$ Neste sentido, José Frederico Marques: “[...] o Cód. De Proc. Penal, apesar de ter mantido grande fidelidade aos postulados essenciais do sistema acusatório, não deixou de sentir os influxos autoritários do Estado Novo. A exemplo do que se fizera na Itália fascista, esqueceram os nossos legisladores do papel e, sob o pretexto de por côbro a formalismos prejudiciais, estruturou as nulidades sob princípios não condizentes com as garantias necessárias ao acusado, além de o ter feito com um lamentável confusionismo e absoluta falta de técnica." MARQUES, José Frederico. Elementos de direito processual penal, v. I. São Paulo: Forense, 1961.

${ }^{16}$ Em consonância com uma visão favorável ao tratamento desigual do indiciado perante o procedimento: NORONHA, Magalhães. Curso de direito processual penal. 7ed., São Paulo: Saraiva, 1974, p.19; TORNAGHI, Hélio Bastos. Instituições de processo penal. v. 2, 3ed. São Paulo: Saraiva, 1977, p.293-294; TOURINHO FILHO, Fernando da Costa. Processo penal. 17 ed. rev. e atual. São Paulo: Saraiva, 1995, p. 203.

${ }_{17}$ PRADO, Geraldo. Sistema acusatório: a conformidade constitucional das leis processuais penais. Rio de Janeiro: Lumen Juris, 2005, p. 193.

${ }^{18}$ GRINOVER, Ada Pellegrini. Liberdades públicas e processo penal: as interceptações telefônicas. Saraiva: São Paulo, 1976, p. 22.
} 
Esta far-se-ia com base em um princípio do devido processo legal de caráter abrangente, pela extensão das garantias processuais (plenitude da defesa do indiciado, acusado ou condenado $^{19}$, isonomia processual - decorrendo disto o contraditório -; juiz imparcial; etc.) a todo o procedimento, incluindo a fase prévia. ${ }^{20}$

Surge, diante do processo penal vigente, a necessidade de conformação ao novo modelo constitucionalmente adotado. Entretanto, o legislador foi incapaz, até o momento, de suprir tal necessidade, seja por conta da edição de legislações esparsas e reformas pontuais nascidas sob momento de pânico e de irracionalidade -, que dificultam a integração sistemática das alterações, seja pelo conformismo da doutrina tradicional; que talvez esteja, ainda, arraigada à visão de 1941, ou simplesmente confortada na segurança jurídica de outrora.

Contudo, a ineficácia legiferante consolida um descompasso entre a ordem constitucional e a estrutura processual penal, que corresponde à causa principal da ineficiência e morosidade processual, bem como da dificuldade de obtenção da verdade processualmente válida, essencial para construção de uma decisão justa.

Para melhor entender as causas e conseqüências deste descompasso, deve-se voltar os olhos para a estrutura e o tratamento das partes no inquérito policial. Como mencionado acima, ocorre um tratamento desigual entre os órgãos de acusação e defesa, por conta da restrição absoluta ao contraditório e exercício do direito de defesa nesta fase $\mathrm{e}^{21}$, o que a torna contrária aos preceitos constitucionais da isonomia processual e da extensão das garantias processuais a todas as fases do processo.

Em relação à arbitrariedade que o art. 14 do Código de Processo Penal atribui à autoridade policial no cumprimento das diligências requeridas pelo “indiciado”, decorre, de

\footnotetext{
${ }^{19}$ Em relação à vinculação hermenêutica da denominação daquele que esteja sujeito à determinada fase do processo penal e a decorrente delimitação de suas garantias processuais, conforme orienta TORNAGHI, op. cit., p.293-294, interessa o esclarecimento constitucional de Rocha Corrêa: “[...] diante da experiência constitucional recente, em que toma cada vez mais relevo a precisão de garantias fundamentais do processo, o desenvolvimento e o estudo da teoria geral do direito processual está longe de ater-se a aspectos meramente formais de procedimento, cuidando de estabelecer todo um arcabouço principiológico dirigido indistintamente aos litigantes em processo penal e civil. É claro que, diante desse novo enfoque, deve-se partir do pressuposto de que o contraditório, como garantia fundamental do 'acusado', aplica-se tanto ao processo judicial em si como, também, à fase que lhe precede, se houver. É evidente que a Constituição, ao referir-se ao 'acusado', não o fez pretendendo ater-se à distinção dogmática existente entre investigado, acusado, condenado etc., antes objetivando proteger qualquer pessoa que esteja sofrendo uma acusação, seja ela de que natureza for (daí a expressão “acusado em geral”). CORRÊA, Cristiane Rocha. op. cit., p. 251.

${ }^{20}$ Cabe aqui ressaltar, desde logo, não se referir à extensão das garantias processuais à fase prévia como forma absoluta, consciente dos momentos em que a restrição à defesa faz-se necessário, fato que justifica falar-se dos mecanismos compensatórios. Sem esta ponderação, difícil será conciliar os expedientes de eficiência e defesa dos direitos do acusado, buscando sempre "uma maior eficiência e funcionalidade do processo penal no interior da sua tradicional função de garantia”. FERNANDES, Fernando A. op. cit., p. 12.
} 
imediato, certo desequilíbrio na relação processual; no que tange à paridade de armas, e; num segundo momento, na fase judicial, pelo contato do juiz com os elementos da fase prévia.

Neste ponto; em razão da ausência de regramentos fixos no que diga respeito ao valor probatório dos elementos produzidos no inquérito policial, ou mecanismos que impeçam o acesso destas informações à fase judicial ${ }^{22}$, constata-se forte influência das investigações preliminares no juízo definitivo da causa, por meio da prática operacional de remissão dos autos de inquérito concluídos, e da determinação legal (art.12 do CPP) do apensamento destes autos à denuncia, passando todos diretamente ao magistrado, sem prévia manifestação da defesa ou audiência das partes, bem como através da produção incidental dos elementos de prova nesta fase inquisitiva ${ }^{23}$, que ganham valor de prova junto aos demais atos instrutórios.

A partir deste contato prévio do magistrado com os elementos de inquérito, ocorre inevitável influência psicológica do convencimento jurisdicional, prejudicando, assim, a eficiência do princípio do contraditório na instrução criminal, pois o juiz passa a apreciar o fato jurídico não só através das provas contraditadas pelas partes, mas também sob a influência dos elementos inquisitivos de inquérito que teve contato.

Portanto, mesmo que a bandeira da igualdade na relação processual e do pleno contraditório seja levantada a plenos pulmões na fase judicial, conforme Aury Lopes $\mathrm{Jr}^{24}$.:

[...] tudo isso cai por terra quando se atribuem poderes instrutórios (ou investigatórios) ao juiz, pois a gestão ou iniciativa probatória é característica essencial do princípio inquisitivo, que leva, por conseqüência, a fundar um sistema inquisitório. A gestão/iniciativa probatória nas mãos do juiz conduz a figura do juiz ator (e não espectador), núcleo do sistema inquisitório. Logo, destrói-se a estrutura dialética do processo penal, o contraditório, a igualdade de tratamento e oportunidade e, por derradeiro, a imparcialidade - o princípio supremo do processo.

\footnotetext{
${ }^{21}$ Em contraposição àqueles que entendem pela desnecessidade da extensão do exercício do direito de defesa já na fase preliminar - TORNAGHI, op. cit -, ressalta-se o entendimento de Paula Bajer, que já identifica nesta fase um interesse do indiciado assegurar a condição de seu ius libertatis contra os indícios de autoria que sobre ele podem recair a partir de pretensa denunciação. COSTA, Paula Bajer Fernandes Martins da. Igualdade no direito processual penal brasileiro. (Coleção de estudos de processo penal Prof. Joaquim Canuto Mendes de Almeida; v.6). São Paulo: RT, 2001, p. 175. Sem mencionar o decorrente estigma social impresso na identidade daquele que se sujeita ao processo penal; Neste mesmo sentido: CORRÊA, Cristiane da Rocha. op cit., p.251; TUCCI, Rogério Lauria. Direitos e Garantias individuais no processo penal brasileiro. 501f. Tese (Livre Docência) Faculdade de Direito, Universidade de São Paulo, 1993, p. 244.

${ }^{22}$ José Frederico Marques admite que, diante do princípio da livre convicção, não se permite regrar o modo de proceder do juiz na descoberta da verdade. No entanto, recomenda que o inquérito deva ser para o juízo um elemento subsidiário que possa complementar o que foi ou será apurado em juízo, bem como, àquele considere às circunstâncias de produção da prova inquisitória e sem contraditório. MARQUES, José Frederico. Elementos de direito processual penal. v. I. São Paulo: Forense, 1997, p.155. Em suma, diante do contato com tais elementos e ausente um controle real, é impossível negar-se, em termos subjetivos, a contribuição dos elementos inquisitivos de inquérito para a formação da livre convicção do juiz.

${ }^{23}$ Apesar da submissão destes elementos a contraditório diferido, há o contato anterior do magistrado com tais elementos.

${ }^{24}$ LOPES JR., Aury Lopes. Introdução crítica ao processo penal: fundamentos da instrumentalidade garantista. Rio de Janeiro: Lumen Juris, 2004, p. 84.
} 
Estarão, dessa forma, ausentes as condições para manutenção da imparcialidade do magistrado, e, portanto, dificultada uma decisão que assegure ao acusado as garantias de um devido processo legal.

Abre-se neste momento um parêntese para fazer menção ao enunciado por Evandro Fernandes de Pontes e Flávio Böechat Albernaz ${ }^{25}$, contido na reunião de estudos do processo penal, coordenada por Fauzi Hassan Choukr, que sintetiza claramente o raciocínio acima:

No Processo Penal Brasileiro, a prática proporciona ao acusador a oportunidade de usar a peça formadora de sua opinio delicti, i.e., os autos da investigação, como prova das imputações feitas em denúncia ou em queixa. Ferindo o princípio do contraditório não só pela falta de participação do ora réu, mas de sua defesa técnica e do próprio juiz na coleta destes elementos. No momento de formação do material de convicção, encontra-se ausente a paridade de armas, inexistindo a própria ação dialética das partes, com base na qual o juiz, que também está ausente, decidirá a questão de mérito.

Portanto, a inserção prematura de um Ministério Público investigador no modelo processual adotado acarretaria um reforço inquisitivo da fase prévia, causado pelo tratamento desigual entre as partes, que tem início nas investigações e se perpetua por todo o processo, em detrimento do indiciado.

Este pretenso reforço inquisitivo dos elementos de investigação ganha pertinência teórica diante da inafastável condição de futura parte processual que o representante do Ministério Público exercerá em juízo, impossibilitando-o, psicologicamente, de promover as investigações de modo imparcial, ainda que, constitucionalmente, a instituição sustente um perfil democrático - art. 127, caput -; para o promotor, no modelo processual brasileiro, não existem mecanismo processuais que o vinculem a uma atuação objetiva ${ }^{26}$.

Em decorrência da permeabilidade dos traços inquisitivos da investigação por todo o processo penal, afetar-se-ia a imparcialidade da decisão jurisdicional, tendo em vista a forma como o magistrado constrói seu convencimento, orientado pelo princípio da livre apreciação das provas.

Em suma, ausente um controle objetivo que filtre aqueles elementos de força inquisitiva; a inserção da atribuição investigativa ministerial - sem o isolamento concreto

\footnotetext{
${ }^{25}$ CHOUKR, Fauzi Hassan. Estudos do processo penal: o mundo à revelia. Campinas: Agá Juris Editora, 2000, p. 137.

${ }^{26}$ Ao contrário do ordenamento processual italiano e português, o órgão ministerial brasileiro não está sujeito ao princípio da objetividade, pelo qual a atuação investigatória do MP - além da atuação por todo o processo -, fica vinculada ao compromisso com a descoberta da verdade dos fatos e com a realização da justiça, independente do intuito punitivo. Este compromisso traduz-se na busca, reunião ou apresentação de elementos de informação que conduzam à acusação ou absolvição do argüido, se assim os fatos indicarem. Mais detalhadamente a respeito deste princípio: DIAS, Jorge de Figueiredo. Direito processual penal. v. I. Coimbra: Coimbra Editora, 1981, e FERNANDES, Fernando A. op. cit. Importante, ainda, observar que a elaboração de mecanismos legais objetivos e a fiscalização jurisdicional desta atividade contribuem para que se realize da forma esperada.
} 
entre o inquérito policial e a instrução judicial, ou sem ao menos um maior equilíbrio entre as partes na fase préviaa ${ }^{27}$, alcançado através de mecanismos de compensação de armas nos casos que exijam uma restrição da defesa -, torna impossível efetivar o caráter acusatório do processo penal brasileiro. Tal impossibilidade persiste mesmo que ainda exista uma distinção funcional e dogmática entre aquelas fases do procedimento.

Portanto, ao contrário de uma inserção pura e simples de atribuições, são necessárias limitações de cunho estrutural do sistema, para que aquelas se efetivem conforme o preceituado.

Independente dos argumentos atualmente levados à baila, é necessário; dentro de um sistema, como é o processo penal, a definição do modelo de estrutura adotado para verificar se a inserção desta nova atribuição gera qualquer instabilidade na essência do modelo, bem como em caso afirmativo, realizar as alterações necessárias para restabelecê-la.

Em relação à tendência internacional de aproximação do Ministério Público na direção das investigações criminais, Evaristo de Moraes ${ }^{28}$, pondera que:

\begin{abstract}
Para tanto, basta operar-se as mudanças necessárias no texto constitucional e na legislação ordinária que, no momento, estão sendo desprezados com a realização de procedimentos investigatórios por parte do Ministério Público, nas órbitas federal e estadual, no Estado do Rio de Janeiro.
\end{abstract}

A inserção pura e simples da atribuição investigativa do Ministério Público no processo penal, sem a mencionada análise e preparo da fase prévia, afeta incisivamente a imparcialidade do magistrado, gerando um descompasso na conjunção dos princípios do devido processo legal, que permite alcançar as instâncias de justiça necessárias à decisão jurisdicional.

Deste descompasso estrutural, ressurge o constante conflito entre as exigências comunitárias de repressão da criminalidade e a liberdade da realização da personalidade individual do imputado, em que o predomínio, tão só, de um órgão acusatório investigante dentro de um sistema que não compatibilize aqueles interesses de forma material, permite o abuso do poder punitivo do Estado, que, sob o pano de fundo do vetor de eficiência, limita desproporcionalmente as possibilidades de livre realização da personalidade ética ${ }^{29}$ do imputado.

\footnotetext{
27 Não se defende, no presente trabalho, a transformação da fase prévia de investigações em instrução contraditória, fato que só contribuiria ainda mais para a burocratização e morosidade do processo, por conta de uma duplicação de atos.

${ }^{28}$ MORAES FILHO, Antonio Evaristo de. O ministério público e o inquérito policial. Revista Brasileira de Ciências Criminais. ano 5, n.19, p. 110. São Paulo: Revista dos Tribunais, 1997.

${ }^{29}$ DIAS, Jorge de Figueiredo. op. cit., p.58 e ss.
} 
Por fim, a atribuição de poderes investigatórios ao Ministério Público ${ }^{30}$ no modelo processual penal vigente seria o suicídio prematuro do Estado Democrático de Direito, em relação ao processo penal, na medida em que ocasionaria a atenuação de garantias indispensáveis à tutela da dignidade humana. ${ }^{31}$

\section{BIBLIOGRAFIA}

AMODIO, Ennio. O modelo acusatório no novo código de processo penal italiano. Revista de Processo. ano.15, n.59, jul-set. São Paulo: RT, 1990, p. 135 - 155.

BASILICO, Ricardo, El procedimento penal en los Estados Unidas. Revista de Ciencias Penales. v.5, [s.i.]: Mario A. Viera, 2000, p. 55 - 84.

CASSEL, Douglass. El sistema processal penal de los Estados Unidos de America. Criminalia. Ano LXIX, n.2, may-ago. México: Porrúa, 2003, p. 163 - 191.

CHOUKR, Fauzi Hassan. As garantias constitucionais na investigação criminal. $425 \mathrm{f}$. Dissertação (Mestrado em Processo Penal) - Faculdade de Direito, Universidade de São Paulo, São Paulo, 1993.

Editora, 2000.

. Estudos do processo penal: o mundo à revelia. Campinas: Agá Juris

COLOMBO, Gherardo. L'acquisizione degli elementi di prova nelle indagini preliminari. Rivista Italiana de Diritto e Procedura Penale. anno XXXV, Milano: Giuffrè, 1992, p.12981315.

CORRÊA, Cristiane da Rocha. O princípio do contraditório e as provas irrepetíveis no inquérito policial. Revista Brasileira de Ciências Criminais. n.60, ano.14, mai-jun. São Paulo: RT, 2006, p. 223-253.

DIAS, Jorge de Figueiredo. Direito processual penal. v. I. Coimbra: Coimbra Editora, 1981.

FERNANDES, Antonio Scarance. Processo Penal Constitucional. $3^{\text {a }}$ ed., ver., atual., ampl. São Paulo: Revista dos Tribunais, 2002.

FERNANDES, Fernando A. O processo penal como instrumento de política criminal. Coimbra: Almedina, 2001.

\footnotetext{
${ }^{30}$ Ademais, deve-se tomar cuidado com a pretensão de transformar o MP em uma super Instituição, na medida em que nele é projetada a imagem do agente solucionador para o combate ao incremento da criminalidade, legitimando lhe, para tanto, poderes coercitivos tanto quanto forem necessários para tal combate, sem observar a compatibilidade, extensão, e conseqüências destas atribuições, diante de uma estrutura processual descompassada constitucionalmente e, portanto, com seu caráter sistemático diluído.

${ }^{31}$ FERNANDES, Fernando A. op. cit., p.14.
} 
Premissa fundamental para uma reforma global do processo penal. Boletim Ibccrim. ano 9, n. 102, maio. 2001, p.12-15.

FRIEDMAN, Lawrence M. Introducción al derecho norteamericano. Trad. Joan Vergé i Grau. Universidad de Stanford. Espanha : Librería Bosh.

GRINOVER, Ada Pellegrini. Liberdades públicas e processo penal: as interceptações telefônicas. Saraiva: São Paulo, 1976.

LOPES JR., Aury Lopes. Introdução crítica ao processo penal: fundamentos da instrumentalidade garantista. Rio de Janeiro: Lumen Juris, 2004.

LOZZI, Gilberto. Profili funzionali e aspetti struturali delle 'indagini preliminari. Rivista Italiana di Diritto e Procedura Penale. v.XXXIII. Milano: Giuffrè, 1990, p. 1276 - 1300.

MARQUES, José Frederico. Elementos de direito processual penal, v. I. São Paulo: Forense, 1961.

MOREIRA, José Carlos Barbosa. O processo penal norte-americano e sua influência. Revista Brasileira de Direito Comparado do Instituito de Direito Comparado Luso-Brasileiro. n.19, Rio de Janeiro: Dinigraf, 2001, p. 227-245.

MORAES FILHO, Antonio Evaristo de. O ministério público e o inquérito policial. Revista Brasileira de Ciências Criminais. ano 5, n.19, p. 110. São Paulo: Revista dos Tribunais, 1997, p. 105-110.

NORONHA, Magalhães. Curso de Direito Processual Penal. 7ed., São Paulo: Saraiva, 1974.

PRADO, Geraldo. Sistema acusatório: a conformidade constitucional das leis processuais penais. Rio de Janeiro: Lumen Juris, 2005.

SILVA SÁNCHEZ, Jesus-María. A expansão do direito penal: aspectos da política criminal nas sociedades pós-industriais. (Trad. Luiz Otávio de Oliveira Rocha) São Paulo: RT, 2002.

TOURINHO FILHO, Fernando da Costa. Processo Penal. 17 ed. rev. e atual. São Paulo: Saraiva, 1995.

TORNAGHI, Hélio Bastos. Instituições de processo penal. v. 2, 3ed. São Paulo: Saraiva, 1977.

TUCCI, Rogério Lauria. Direitos e Garantias individuais no processo penal brasileiro. 501f. Tese (Livre Docência) - Faculdade de Direito, Universidade de São Paulo, 1993.

ZAGREBELSKY, Vladimiro. Modello accusatorio e deontologia dei comportamenti processuali nella prospettiva comparatistica. Rivista Italiana di Diritto e Procedura Penale. Milano: Giuffrè, 1993, p. 434 - 492. 